УДК 378

Науч. спец. 13.00.01

DOI: 10.36809/2309-9380-2019-25-127-132

\section{НАУЧНО-ПЕДАГОГИЧЕСКАЯ ШКОЛА Н. В. ЧЕКАЛЕВОЙ*}

Целью статьи является теоретический анализ направлений научно-исследовательской работы научно-педагогической школы Н. В. Чекалевой, определение показателей ее сфрормированности.

Ключевые слова: научная школа, научно-педагогическая школа.
C. Г. Чухин, Е. В. Чухина

S. G. Chukhin, E. V. Chukhina

\title{
SCIENTIFIC AND PEDAGOGICAL SCHOOL OF N. V. CHEKALEVA
}

The purpose of the article is a theoretical analysis of the areas of research work ofscientific and pedagogical schoolof N.V. Chekaleva, determination of indicators of its formedness.

Keywords: scientific school, scientific and pedagogical school.

Под научной школой нами понимается системное оформление научных идей, научных сообществ, которые придерживаются данных идей. Создание научных школ осуществляется благодаря влиянию лидеров, эрудиции, кругу их научных интересов и стилей научной деятельности, которые обладают решающим значением в привлечении новых коллег. Научное сообщество, как правило, определяет одно из основных направлений научных разработок, оно формируется в зависимости от становления университетского образования. Научно-исследовательская работа ведущих университетов предполагает в качестве основного принципа в университетском образовании то, что преподаванием наук может заниматься только человек, который одновременно осуществляет определенное научное исследование. В процессе совершенствования результативности при выполнении научного исследования у сложившихся научных коллективов возникает потребность в получении официального статуса - научная школа. Такая научная школа объединяет исследовательские сообщества, которые отличаются значительной степенью научных достижений по признанным научным направлениям; данные научные сообщества характеризуются устойчивыми научными традициями, признаком преемственности нескольких поколений ученых в процессе воспитания исследовательских кадров; руководит данным научным сообществом авторитетный ученый, как правило, доктор наук в данной научной области. В качестве основных критериев выступает: высокий уровень качества научного исследования, который подтверждается опубликованием научных материалов (монография, статьи) в рецензируемых научных источниках, свидетельствами об изобретениях, наличием фринансирования внешними организациями, систематическим характером в подготовке научно-педагогических сотрудников, имеющих высшую квалификацию (защита диссертаций кандидатского и докторского уровня), наличием прочной научной связи.

Надежда Викторовна Чекалева - широко известный в профессиональном сообществе специалист в сфере подготовки педагогических кадров в системе высшего обра- зования. Научные исследования и практическая деятельность Надежды Викторовны в сфрере образования отражают основные направления подготовки будущего педагога. Результаты исследований и их внедрение в практику способствуют созданию разнообразных подходов в подготовке будущего педагога, модернизации образовательного процесса в вузе, разработке комплексной оценки результативности обучения студентов. Надежда Викторовна Чекалева активный участник и научный руководитель коллективных исследований проблем профессионального образования, модернизации педагогического образования: ее работа по подготовке педагогических кадров содействует расширению и обновлению реализуемых образовательных программ в магистратуре по направлениям «Педагогическое образование», «Психолого-педагогическое образование», «Специальное образование»; развивает введение сетевого, кластерного подхода в уровневой подготовке педагогических кадров.

Например, формирование качеств, которые способствуют актуализации и совершенствованию творческого потенциала будущего учителя в процессе учебно-педагогической работы, получило рассмотрение в диссертации С. М. Баташовой [1]; педагогические условия, направленные на общепрофессиональную подготовку будущих учителей к деятельности в основной школе, были выявлены и обоснованы в диссертационном исследовании Ю. В. Мартыновой (Завгородневой) [2]; проблема взаимосвязи теоретического и практического знания, преодоления его бессистемного использования при изучении педагогических дисциплин разрабатывалась Л. П. Берестовской [3]; вопросы организации образовательного процесса формирующего у студентов активное отношение к учебной деятельности получили освещение в кандидатском исследовании И. И. Некрасовой [4]; особенности образовательного выбора студентов Германии, актуальные для заимствования при разработке стратегий изменения образовательного выбора студентов России, были выявлены и обоснованы в диссертационной работе Т. О. Соловьевой [5].

“ Исследование выполнено при поддержке РФФИ; проект № 18-413-550001 «Становление научно-педагогических школ г. Омска как фрактор развития регионального образовательного пространства (вторая половина XX — начало XXI вB.)».

The study was supported by the Russian Foundation for Basic Research; project № 18-413-550001 "The Formation of Scientific and Pedagogical Schools in the City of Omsk as a Factor in the Development of Regional Educational Space (the second half of the XX - beginning of the XXI centuries)". 
Н. В. Чекалева разработала теоретические основы учебно-методического обеспечения процесса профессиональной подготовки в педагогическом вузе в рамках кластерного подхода; ею обоснованы современные подходы и организационные модели подготовки педагогических кадров в условиях сетевого регионального взаимодействия; предложена концепция оценки качества повышения квалификации педагогов в инновационном образовании; осуществлено исследование изменений в образовательном процессе современного вуза.

Например, вопросы, связанные с интеграцией психолого-педагогической и методической подготовки студентов в высшем педагогическом образовании, обоснованы в исследовании Е. В. Чухиной [6]; обоснование педагогического проектирования в процессе подготовки будущих учителей к работе в условиях инновационной деятельности предложила Н. А. Дука [7]; выявление и обоснование условий организации образовательного процесса, обеспечивающих успешность подготовки будущего учителя к профессиональной деятельности, было осуществлено в работе А. М. Берестовского [8]; педагогические условия, обеспечивающие реализацию индивидуально-образовательного маршрута в подготовке студента к профессиональной педагогической деятельности, были выявлены и обоснованы в кандидатской диссертации В. В. Лоренц [9]; теоретическое обоснование технологии организации взаимодействия преподавателя и студентов, соответствующего инновационному образовательному процессу современного педагогического университета, было осуществлено в исследовании А. Ф. Кабирова [10].

Значимость проведенных исследований для развития теории и практики подготовки современного учителя в процессе уровневого педагогического образования заключается в том, что Н. В. Чекалевой обоснована роль регионального профессионально-педагогического кластера в сетевом взаимодействии вузов; выявлены изменения в деятельности преподавателя вуза в контексте инновационного образования, а также системные изменения в школьном образовании как фрактор изменений в повышении квалификации педагогических кадров; предложены инновационные подходы в подготовке будущих специалистов, к оценке компетенций студентов вуза; рассмотрена подготовка педагогических кадров к работе в условиях инновационного образования.

Например, новые способы, обеспечивающие развитие профессиональной компетентности и индивидуальной мобильности студентов в учреждениях профессионального педагогического образования, получили рассмотрение в исследовании И. К. Дракиной [11]; выявление и обоснование условий в структуре общепрофессиональной подготовки студентов для развития интеллектуальных умений при решении учебно-профессиональных задач осуществлено в исследовательской работе С. А. Рассады [12]; исследованию условий в подготовке студентов педагогического вуза к формированию эмоционально-предметной образовательной среды посвящена диссертационная работа И. В. Феттер [13]; выявление и обоснование организационно-педагогических условий развития социально-правовой компетентности студентов в освоении содержания педагогических дисциплин было осуществлено в диссертационной работе
Т. С. Волох [14]; анализу и обоснованию ведущих тенденций в изменении оценивания подготовки студентов педагогических вузов к будущей педагогической работе посвящено исследование С. В. Назарова [15]; проблематика выявления и обоснования сущности и условий научно-методического сопровождения инновационных процессов в сельской школе получила рассмотрение в работе Е. В. Шушаковой [16]; выявление и теоретическое обоснование содержания, методов и средств процесса фрормирования педагогических знаний, которые необходимы в профессиональном развитии менеджера сестринского дела, осуществлено в исследовании О. М. Сальниковой [17]; развитие поликультурной компетентности будущего специалиста (на примере Академии МВД) получило рассмотрение в исследовании Е. М. Щегловой [18]; речевая компетентность врача, выявление ее содержания и критериев оценки стали предметом исследования М. Б. Мусохрановой [19]; разработка подходов к содержанию и структуре учебной книги, которая соответствует актуальным требованиям профессиональной подготовки специалиста, была осуществлена в научной работе 3. А. Мендубаевой [20].

В публикациях Н. В. Чекалевой обосновано влияние регионального образовательного кластера на качество педагогического образования; раскрыты возможности кластерного подхода в организации сетевого взаимодействия в подготовке педагогических кадров для региона; разработана концепция развития педагогического образования в регионе, направленная на повышение качества подготовки педагогов, которая включает в себя описание специфических условий, определяющих контексты профессиональной педагогической деятельности в Омской области, преимущества и потенциальные риски, проблемы и приоритетные направления развития педагогического образования, задачи на каждом из этапов подготовки педагога, критерии результативности концепции, примерные мероприятия «дорожной карты» по ее реализации. Н. В. Чекалева является научным руководителем образовательных программ магистратуры «Высшее образование», подготовки молодых исследователей по педагогическим наукам, реализуемой в Омском государственном педагогическом университете (ОмГПУ) с 2000 г. В плане разработки научно-методического сопровождения реализации этих программ разработаны и внедрены в образовательную практику маршруты подготовки кадров высшей квалификации в аспирантуре; представлена работа научного семинара для аспирантов и соискателей в рамках выпускающей кафедры.

Например, сущность, этапы и тенденции в развитии научно-дидактического знания об образовательном процессе высшей школы проанализированы, обоснованы и экспериментально подтверждены в докторской диссертации Н. С. Макаровой по теме «Развитие дидактического знания об образовательном процессе в высшей школе» [21]; обоснование направлений в построении профессиональной подготовки магистратуры педагогического вуза было реализовано в диссертационном исследовании Е. Г. Никулиной [22]; комплексная оценка образовательных результатов студентов магистратуры, принципы, цели, фрормы, методы, средства, субъекты и инструменты ее осуществления получили обоснование в научной работе А. Д. Каримовой [23]; в 2017 г. 
было защищено докторское исследование Ю. Б. Дроботенко по выявлению ведущих тенденций, вызванных модернизацией педагогического образования в профеессиональной подготовке студентов педагогического вуза [24].

Н. В. Чекалева являлась научным руководителем ряда проектов, выполняемых по заказу Министерства образования и науки РФ: «Сетевое взаимодействие в подготовке педагогических кадров Омского региона» (РГНФ, Министерство образования Омской области, 2015); «Изменения в деятельности учителя в условиях реализации "Профессионального стандарта педагога" и разработка моделей профессионального экзамена на должность учителя» (Госзадание МОН РФ, 2015); «Подготовка педагогов инклюзивного образования на базе регионального ресурсного центра» (РГНФ, 2014); «Базовая кафедра педвуза в организациях общего образования: новый формат научно-методической работы» (Госзадание МОН РФ, 2016).

На основе научно-исследовательской и педагогической работы Н. В. Чекалевой и при ее непосредственном участии разработаны и реализуются в практике работы ОмГПУ и других педагогических вузов страны проекты, направленные на развитие подготовки педагогов и на преодоление противоречий между требованиями Профессионального стандарта и образовательной практикой педвузов (проекты «Педагогический класс», «Виртуальный педагогический класс», «Воскресный малый университет», «Педагогическая интернатура», «Проектирование модулей практикоориентированной подготовки бакалавров и магистров образования», «Профессионально-педагогический кластер», «Итоговая государственная аттестация на основе практикоориентированных задач: междисциплинарный экзамен», «Базовая кафедра» и др.). Эффективность научной деятельности Н. В. Чекалевой подтвердилась положительными результатами разработки и реализации научно-методического обеспечения образовательного процесса в рамках Стратегического развития ОмГПУ (2013-2018), участием в сетевом объединении «Педагогические вузы России».

Например, проблема содержания и технологии подготовки студентов бакалавриата к профессиональной педагогической деятельности в информационно-образовательном пространстве получила рассмотрение и решение в диссертационной работе Э. Р. Диких [25]; аудиовизуальная поддержка студента как особый вид организации педагогического сопровождения, отражающий потребности педагогической науки и практики по изменению содержания в профессиональной подготовке, которая призвана соответствовать тенденциям развития информационного общества, была обоснована в кандидатской диссертации Е. Н. Котенко [26]; проблема готовности преподавателей вуза к эффективной работе в системе дистанционного обучения решалась в работе П. В. Закотновой [27].

Значительного внимания заслуживает научно-педагогическая и общественная деятельность Н. В. Чекалевой в сфере инклюзивного и специального образования. Она была научным руководителем российско-канадского проекта по работе с инвалидами, является инициатором научно-методических семинаров, руководителем проекта «Организация и содержание подготовки педагогов к деятельности в условиях инклюзивного образования», деятельности цент- ров по развитию инклюзивного и специального образования. Ею были разработаны модель и программа регионального ресурсного центра по подготовке педагогов инклюзивного образования; определены содержание и технология такой подготовки; обоснованы функции, содержание и направления деятельности тренера инклюзивного образования, осуществляющего внутрифирменное обучение.

Например, содержание и технология подготовки педагогов к работе в условиях инклюзивного образования рассматривалось в работе О. С. Кузьминой [28]; технологии обеспечения компетентности личной безопасности обучающихся школ Израиля, которые могут успешно применяться в условиях российской школы, были обоснованы в исследовании Д. А. Шпакина [29]; выявление педагогических условий, направленных на самореализацию одаренным ребенком своих личностных возможностей и актуализации им своей значимости, что в прогрессии должно проявляться в позитивной социализации, стало предметом научного анализа О. С. Парц [30].

В настоящее время Надежда Викторовна Чекалева работает директором института инновационного и инклюзивного образования ОмГПУ, успешно заведует кафедрой педагогики, является исполнительным директором профессионально-педагогического кластера Омской области. К достижениям ее деятельности можно отнести участие ОмГПУ в Федеральной программе модернизации педагогического образования; развитии инновационных педагогических и социальных проектов; подготовку кадров высшей научной квалификации; ориентацию на сохранение традиций в сфере образования и инициирование новых педагогических идей, что оказывает существенное влияние на подготовку будущего педагога; использование научно-образовательной среды для профессионального роста не только преподавателей вуза, но и коллег из сферы образования.

Н. В. Чекалева активно сотрудничает с Министерством образования Омской области (член коллегии), департаментом образования Администрации г. Омска (член коллегии). Надежда Викторовна - член Общественной палаты Омской области (комиссия по образованию), научный руководитель Федеральной экспериментальной площадки «Нововаршавский район», член Координационных советов при Правительстве Омской области, член конкурсных комиссий при Министерстве образования Омской области, член Федерального учебно-методического объединения высшего образования «Образование и педагогические науки». Надежда Викторовна пользуется большим авторитетом в профрессиональном сообществе, но главное то, что это позволяет ей не только активно выстраивать взаимодействие учреждений системы образования и педагогического вуза, но и устойчиво находиться в актуальном поле проблем школьного и педагогического образования, вносить существенные коррективы в содержание и технологии подготовки педагогических кадров, оперативно откликаться на запросы регионального рынка педагогического труда.

Например, вопросы управления развитием муниципальной системы образования на основе стратегического планирования рассматривались в кандидатской диссертации В. И. Гама [31]; выявление и обоснование условий развития профессиональной компетентности педагогов малых 
городов Крайнего Севера было осуществлено в диссертационном исследовании Е. В. Майной [32]; вопросы, связанные с обеспечением педагогического управления НОУ с целью удовлетворения разнопланового социального заказа со стороны субъектов образовательного процесса и требований качества образования обучающихся, рассматривались в кандидатской диссертации А. С. Маврина [33]; проблема обоснования путей формирования и реализации миссии современной сельской школы рассматривалась в кандидатском исследовании 3. А. Халюты [34].

С 27 апреля 2017 г. Н. В. Чекалева является членом-корреспондентом Российской академии образования, состоит в отделении философии образования и теоретической педагогики; академик Международной академии наук педагогического образования; председатель диссертационного совета Д 212.177.02 по специальностям 13.00.01 «Общая педагогика, история педагогики и образования»; 13.00 .08 «Теория и методика профессионального образования»; 13.00 .02 «Теория и методика обучения и воспитания (по областям и уровням образования)». Значительное место в своей работе она уделяет качеству диссертационных исследований, проявляя одновременно высокую требовательность и уважение к соискателям. Надежда Викторовна является членом редакционных советов и редакционных коллегий (Российский государственный педагогический университет им. А. И. Герцена, Томск); ее многочисленные научные труды заслуженно признаны в научном сообществе. Н. В. Чекалева является почетным работником высшего профессионального образования РФ, заслуженным работником образования Омской области. Научные результаты и практическая деятельность в области совершенствования подготовки будущих педагогов Н. В. Чекалевой отмечены: нагрудным знаком ОмГПУ «За доблестный труд», медалью 300-летия Омска, знаком отличия Федеральной службы государственной статистики медалью «За заслуги в проведении Всероссийской переписи населения 2010 года» [35].

Активная научная деятельность Н. В. Чекалевой позволила создать научно-педагогическую школу, в которую входит более 45 исследователей, осуществляющих научный поиск в области подготовки педагогических кадров:

- подготовка будущих педагогов в условиях изменяющегося социума (Л. П. Берестовская [3], С. М. Баташова [1], С. А. Рассада [12], Ю. В. Мартынова (Завгороднева) [2], Э. Р. Диких [25], Е. В. Чухина [6]);

- научные основы проектирования образовательного процесса в вузе (Н. А. Дука [7], А. М. Берестовский [8], В. В. Лоренц [9]);

- формы и технологии подготовки будущего учителя к профессиональной деятельности (И.В.Феттер [13], Е. Н. Котенко [26], Е. А. Кулькина [36], И. И. Некрасова [4], П. В. Закотнова [27], И. А. Дегтярева [37], Т. С. Волох [14], Э. Ж. Мухамедина [38], А. Ф. Кабиров [10]);

- изменения в профессиональной подготовке студентов вуза (Ю. Б. Дроботенко [39], С. В. Назаров [15], О. М. Сальникова [17], Е. М. Щеглова [18], М. Б. Мусохранова [19], 3. А. Мендубаева [20], А. Д. Каримова [23], Е. А. Бобер [40],

Е. Г. Никулина [22]);

- изменения образовательного процесса в общем и высшем образовании (Н. С. Макарова [41], О. С. Парц
[30], А. В. Богдашин [42], А. Г. Рядовой [43], О. С. Кузьмина [28], И. К. Дракина [11], В. И. Гам [31], Е. В. Майная [32], А. С. Маврин [33], 3. А. Халюта [34], Е. В. Шушакова [16], Т. О. Соловьева [5], Д. А. Шпакин [29]).

Итак, научно-педагогическая школа Надежды Викторовны Чекалевой обладает всеми необходимыми признаками научной школы [44]: 1) наличие создателя научной школы - крупного ученого, владеющего уникальным способом работы и сплачивающего вокруг себя членов коллектива для выполнения определенных исследовательских целей и программ; обладающего умением отбирать творческую молодежь и учить ее исследовательскому мастерству; обеспечивающего особую научную атмосферу в коллективе; поощряющего самостоятельность мышления и инициативу его членов; 2) наличие предлагаемой создателем школы исследовательской программы (научного направления), конституирующей школу как социальную целостность, соединяющей в себе перечень проблем, на решение которых ориентируется научно-педагогический коллектив; 3) наличие в работе школы взаимосвязанных педагогической и исследовательской функций, диалектического единства процессов познания и передачи знаний, навыков и умений исследовательской работы, образцов и общих традиций; 4) наличие определенного стиля научной и педагогической работы, включающего особую моральную атмосферу, благоприятный психологический климат, некоторые нравственные каноны, особые отношения между членами школы, систему коммуникаций, определяющую рабочую атмосфреру в школе.

1. Баташова С. М. Подготовка студентов педагогического вуза к профессиональной деятельности при изучении педагогических дисциплин : автореф. дис. ... канд. пед. наук. Омск, 1998. 17 с.

2. Завгороднева Ю. В. Подготовка будущего учителя к работе в основной школе : автореф. дис. ... канд. пед. наук. Омск, 2006. 23 с.

3. Берестовская Л. П. Взаимосвязь теоретических и практических знаний студентов при изучении педагогических дисциплин : автореф. дис. ... канд. пед. наук. Омск, 1997. 18 с.

4. Некрасова И. И. Взаимосвязь общего и профессионального образования в формировании познавательной активности студентов : автореф. дис. ... канд. пед. наук. Омск, 2004. 23 с.

5. Дука Т. О. Образовательный выбор студентов университетов России и Германии : автореф. дис. ... канд. пед. наук. Омск, 2010. 23 с.

6. Чухина Е. В. Интеграция психолого-педагогических и методических знаний в общепрофессиональной подготовке будущего учителя : автореф. дис. ... канд. пед. наук. Омск, 2006. 20 c.

7. Дука Н. А. Педагогическое проектирование как условие подготовки будущего учителя к инновационной деятельности : автореф. дис. ... канд. пед. наук. Омск, 1999. 23 с.

8. Берестовский А. М. Проектирование образовательно-профессиональных технологий подготовки специалиста в педагогическом вузе : автореф. дис. ... канд. пед. наук. Омск, 2002. 18 c. 
9. Лоренц В. В. Проектирование индивидуально-образовательного маршрута как условие подготовки будущего учителя к профессиональной деятельности : автореф. дис. ... канд. пед. наук. Омск, 2001. 23 с.

10. Кабиров А. Ф. Организация взаимодействия преподавателя и студентов в инновационном образовательном процессе педагогического вуза : автореф. дис. ... канд. пед. наук. Омск, 2006. 19 с.

11. Дракина И. К. Организационно-управленческие условия построения педагогической практики будущего учителя в современной школе : автореф. дис. ... канд. пед. наук. Омск, 2000. 22 с.

12. Рассада С. А. Развитие интеллектуальных умений будущих учителей в структуре общепрофрессиональной подготовки : автореф. дис. ... канд. пед. наук. Омск, 2005. 22 с.

13. Феттер И. В. Подготовка будущего учителя к созданию эмоционально-предметной среды : автореф. дис. ... канд. пед. наук. Омск, 2001. 20 с.

14. Волох Т. С. Развитие социально-правовой компетентности будущего учителя : автореф. дис. ... канд. пед. наук. Омск, 2006. 19 с.

15. Назаров С. В. Изменения в оценке готовности выпускников педагогического вуза к профессиональной деятельности : автореф. дис. ... канд. пед. наук. Омск, 2010. 23 с.

16. Шушакова Е. В. Научно-методическое сопровождение инновационных процессов в сельской школе : авторефр. дис. ... канд. пед. наук. Омск, 2008. 22 с.

17. Сальникова О. М. Педагогические знания в профессиональной подготовке специалистов в техническом вузе : авторефр. дис. ... канд. пед. наук. Омск, 2001. 21 с.

18. Щеглова Е. М. Развитие поликультурной компетентности будущих специалистов (на примере курсантов Академии МВД) : автореф. дис. ... канд. пед. наук. Омск, 2005. $23 \mathrm{c}$.

19. Мусохранова М. Б. Формирование речевой компетентности будущего врача в процессе обучения иностранному языку : автореф. дис. ... канд. пед. наук. Омск, 2002. $21 \mathrm{c}$.

20. Мендубаева 3. А. Современная учебная книга в системе учебно-методического комплекса общепрофрессиональной подготовки студентов вуза : автореф. дис. ... канд. пед. наук. Чита, 2013. 24 с.

21. Макарова Н. С. Развитие дидактического знания об образовательном процессе в высшей школе : автореф. дис. ... д-ра пед. наук. Омск, 2015. 43 с.

22. Никулина Е. Г. Изменения в содержании профессиональной подготовки в магистратуре педагогического вуза : автореср. дис. ... канд. пед. наук. Омск, 2015. 23 с.

23. Каримова А. Д. Комплексная оценка образовательных результатов студентов магистратуры : автореф. дис. ... канд. пед. наук. Чита, 2013. 24 с.

24. Дроботенко Ю. Б. Изменения профессиональной подготовки студентов педагогического вуза в условиях модернизации педагогического образования Российской Федерации : автореф. дис. ... д-ра пед. наук. Омск, 2016. 42 с.

25. Диких Э. Р. Подготовка студентов бакалавриата к профессиональной педагогической деятельности в информационно-образовательном пространстве : авторефр. дис. ... канд. пед. наук. Омск, 2014. 24 с.
26. Котенко Е. Н. Аудиовизуальная поддержка студентов при решении профессионально-педагогических задач (на примере педагогических дисциплин) : автореф. дис. ... канд. пед. наук. Омск, 2003. 19 с.

27. Закотнова П. В. Подготовка преподавателей вуза к деятельности в системе дистанционного обучения : автореф. дис. ... канд. пед. наук. Омск, 2004. 22 с.

28. Кузьмина О. С. Подготовка педагогов к работе в условиях инклюзивного образования : автореф. дис. ... канд. пед. наук. Омск, 2015. 22 с.

29. Шпакин Д. А. Становление компетентности личной безопасности в школах Израиля и России : автореф. дис. ... канд. пед. наук. Омск, 2012. 24 с.

30. Парц О. С. Педагогические условия самореализации одаренных детей (на материале дополнительного образования) : автореф. дис. ... канд. пед. наук. Омск, 2007. 23 с.

31. Гам В. И. Стратегическое планирование в управлении развитием муниципальной системы образования (на примере города Омска) : автореф. дис. ... канд. пед. наук. Омск, 2001. 25 с.

32. Майная Е. В. Организационно-педагогические условия развития профессиональной компетентности педагогов (на примере муниципальной системы образования малого города Крайнего Севера) : автореф. дис. ... канд. пед. наук. Омск, 2006. 24 с.

33. Маврин А. С. Педагогическое управление негосударственным образовательным учреждением в условиях современного социума : автореф. дис. ... канд. пед. наук. Омск, 2009. 25 с.

34. Халюта 3. А. Педагогические условия формирования и реализации миссии сельской школы : авторефр. дис. ... канд. пед. наук. Омск, 2001. 22 с.

35. Энциклопедия города Омска : в 3 т. Т. 3. Омск в лицах. Кн. 2. Л-Я / под ред. И. А. Кольца, Г. А. Павлова, А. П. Толочко. Омск : Издатель-Полиграфист, 2011. 692 c.

36. Кулькина Е. А. Педагогические условия организации работы студентов с учебными текстами по педагогике : автореф. дис. ... канд. пед. наук. Омск, 2003. 22 с.

37. Дегтярева И. А. Развитие социально-профессиональной компетентности будущих мастеров производственного обучения в образовательном процессе вуза : автореф. дис. ... канд. пед. наук. Омск, 2016. 25 с.

38. Мухамедина Э. Ж. Организационно-педагогические условия развития готовности начинающего преподавателя к профессиональной деятельности в военном вузе : автореф. дис. ... канд. пед. наук. Омск, 2016. 22 с.

39. Дроботенко Ю. Б. Организация самостоятельной работы студентов в вузе при изучении педагогических дисциплин : автореф. дис. ... канд. пед. наук. Омск, 2006. $25 \mathrm{c}$.

40. Бобер Е. А. Становление профессиональных ценностных ориентаций студентов медицинского колледжа в образовательном процессе : автореф. дис. ... канд. пед. наук. Омск, 2014. 24 с.

41. Макарова Н. С. Освоение историко-педагогического знания в структуре общепрофессиональной подготовки будущих учителей : автореф. дис. ... канд. пед. наук. Омск, 2004. 21 c. 
42. Богдашин А. В. Развитие ключевых компетенций подростков в образовательном процессе учреждения дополнительного образования : автореф. дис. ... канд. пед. наук. Омск, 2012. 23 с.

43. Рядовой А. Г. Управление процессом гражданскопатриотического воспитания студентов в учреждении сред-

УДК $37.088+613.86$

Науч. спец. 13.00 .01

DOI: 10.36809/2309-9380-2019-25-132-136

\section{ОСОБЕННОСТИ ПРОФЕССИОНАЛЬНОГО ЗДОРОВЬЯ СОВРЕМЕННОГО ПЕДАГОГА}

В статье рассматривается актуальная проблема современного образования - профессиональное здоровье современного педагога. Проведен анализ рисков и угроз нарушений профессионального здоровья. Обоснованы основные компоненты профессионального здоровья современного педагога: уровень профессиональной продуктивности и психологического здоровья, устойчивость к стрессу, склонности к развитию синдрома «психического выгорания», степень профессиональной деформации и общие психологические ресурсы. Проведено эмпирическое исследование, направленное на изучение особенностей профессионального здоровья современного педагога. В результате было установлено, что основной угрозой является синдром «психического выгорания». Подведены итоги и определены направления профилактики нарушений профессионального здоровья педагога.

Ключевые слова: профессиональное здоровье, психологический стресс, синдром «психического выгорания», профессиональная деформация личности, педагогическая деятельность. него профессионального образования : автореф. дис. ... канд. пед. наук. Омск, 2010. 23 с.

44. Владимиров А. И. О научных и научно-педагогических школах. М. : Недра, 2013. 61 с.

(C) Чухин С. Г., Чухина Е. В., 2019

S. V. Scherbakov, Ja. B. Lev, E. G. Ozhogova

\section{SPECIAL ASPECTS OF PROFESSIONAL HEALTH OF THE MODERN TEACHER}

The article deals with the actual problem of modern education-professional health of the modern teacher. The analysis of risks and threats of violations of professional health is carried out. The authors substantiated the basic components of professional health of a modern teacher: the level of professional productivity and psychological health, resistance to stress, tendency to the development of the syndrome of "mental burnout", the degree of professional deformation and the total psychological resources. An empirical research aimed at studying the features of professional health of a modern teacher. As a result, it was found that the main threat is the syndrome of "mental burnout". The results are summed up and the directions for the prevention of violations of ateacher's professional health are defined.

Keywords: professional health, psychological stress, syndrome of "mental burnout", professional deformation of personality, pedagogical activity.

Профессиональная деятельность педагога предполагает выполнение не только обучающей, воспитательной, развивающей функций, но и сохранение здоровья учеников и воспитанников. Однако реализация здоровьесберегающей функции невозможна, если здоровье самого педагога находится под угрозой [1].

К сожалению, уровень здоровья педагога остается низким. В исследовании О. Ф. Жукова было выявлено, что только 33 \% учителей считают себя здоровыми, около 70 \% педагогов отмечают нарушения в состоянии здоровья. При этом установлено, что лишь 2,8 \% учителей обращаются за помощью к врачам и оформляют больничный лист, т. е. учителя предпочитают переносить болезнь «на ногах», продолжая работать. «Лидерами» в структуре заболеваемости педагогов являются патология органов зрения - 68 \%; сердечно-сосудистые заболевания - $48 \%$; заболевания опорно-двигательного аппарата - 44 \%. Причем учителя в своих анкетах нередко указывали несколько заболеваний [2, с. 50].

Нельзя не согласиться со мнением профессора А. Г. Маклакова, что сохранение здоровья и профессио- нального долголетия специалистов является не только индивидуальной проблемой человека, но и важной государственной задачей [3].

В настоящее время нет единого определения понятия «профессиональное здоровье». Мы разделяем точку зрения В. А. Пономаренко, который понимает профессиональное здоровье как возможность организма сохранять компенсаторные и защитные механизмы, обеспечивающие работоспособность во всех условиях и на всех этапах профессиональной деятельности. Эта концепция рассматривает профессиональное здоровье как совокупность физиологических и психосизиологических параметров, обеспечивающих высокую надежность деятельности и профессионального долголетия [3, с. 41]

Если говорить об угрозе профессионального здоровья педагога, то в первую очередь важно обратиться к специфике профессионально-педагогической деятельности. Подверженность негативным профессионально обусловленным психическим состояниям заложена в специфике профессионально-педагогической деятельности: эмоциональная напряженность и когнитивная сложность педагогической 